\title{
PSICOLOGIA, FORMAÇÃO DE PSICÓLOGOS E A ESCOLA: DESAFIOS CONTEMPORÂNEOS
}

\author{
Flávia da Silva Ferreira Asbahr ${ }^{*}$ \\ Edna Martins ${ }^{\#}$ \\ Beatriz Pinheiro Machado Mazzolini"
}

\begin{abstract}
RESUMO. A atuação do psicólogo na educação cresce nos últimos anos, em instituições educativas e no atendimento à queixa escolar, mas ainda é comum, em diversos cursos de graduação, psicólogos se formarem sem ter tido contato direto com uma escola. Esse fato reduz os fenômenos escolares a questões meramente psicológicas e, sobretudo, patológicas, e coexiste com práticas apoiadas na compreensão dos elementos que constituem a subjetividade em sua relação com os processos educativos. Discutimos, a partir do relato de experiência docente, aspectos que são fundamentais para uma proposta de formação do psicólogo que tem como referência a inserção do estudante de psicologia em espaços educativos por meio de visitas a instituições e de estágios na área. Essa proposta desdobra-se em duas modalidades: a disciplina Problemas de Aprendizagem e o estágio Intervenção clínica em processos de aprendizagem. Tal inserção cria a possibilidade de o futuro psicólogo contactar-se com o cotidiano escolar e deparar-se com determinações que vão além da imediata relação dual psicólogo-usuário.
\end{abstract}

Palavras-chave: Formação do psicólogo; psicologia escolar; fracasso escolar.

\section{PSYCHOLOGY, PROFESSIONAL PREPARATION OF THE PSYCHOLOGIST AND THE SCHOOL: CONTEMPORARY CHALLENGES}

\begin{abstract}
The psychologist's practice in education is growing in recent years in educational institutions and the work with to the complaint school. But it is still common in many undergraduate courses, psychologists graduating without having any contact with an elementary or high school. This fact reduces the educational phenomena to psychological issues and, above all, pathological ones, and coexists with practices based upon an understanding of the elements of subjectivity in its relation with the educational processes. We discuss, based on docent experience report, aspects that are critical to a proposal for the formation of psychologist that has as reference to the insertion of psychology students in educative spaces through visits to the institutions and traineeships in the area. The proposal unfolds in two models: the discipline Learning Problems and the traineeship Clinical Intervention in Learning Processes. This integration creates the possibility for the future psychologist to be in contact with the school routine, and to face with determinations that go beyond the immediate dual relationship psychologist-user.
\end{abstract}

Key words: Professional preparation of the psychologist; educational psychology; school failure.

\section{PSICOLOGÍA, FORMACIÓN DE PSICÓLOGOS Y LA ESCUELA: DESAFÍOS CONTEMPORÁNEOS}

RESUMEN. La actuación de los psicólogos en la educación crece en los últimos años, en las instituciones educativas y en la asistencia a la demanda de la escuela. Sin embargo, todavía es común en las graduaciones de psicología que los estudiantes terminen el curso sin tener contacto con una escuela. Las prácticas que reducen los fenómenos educativos a problemas psicológicos coexisten con las prácticas basadas en la comprensión de los elementos que componen la subjetividad en su relación con los procesos educativos. Presentamos, a partir del informe de nuestra experiencia docente, una propuesta para la formación de los psicólogos que tiene como referencia la inserción de los estudiantes de psicología en los espacios educativos a través de visitas a las instituciones escolares y de prácticas/pasantías en el área. La propuesta se divide en dos modalidades,

Doutora em Psicologia Escolar e do Desenvolvimento Humano pela Universidade de São Paulo. Professora da Unianhanguera/Uniflan, Campus de Leme-SP, Brasil.

\# Doutora em Educação (Psicologia da Educação) pela Pontifícia Universidade Católica de São Paulo. Professora do Departamento de Educação da Universidade Federal de São Paulo, Campus de Guarulhos , Brasil.

II Doutora em Psicologia Escolar e do Desenvolvimento Humano pela Universidade de São Paulo. Professora da Universidade Paulista, Campus Marquês de São Vicente-SP, Brasil. 
la asignatura Problemas de aprendizaje y la práctica Intervención clínico en el proceso de aprendizaje. La inserción del futuro psicólogo en la escuela crea la potencialidad de que él se impacte con la rutina de la escuela y con las determinaciones que van más allá de la inmediata relación del psicólogo con el usuario.

Palabras-clave: Formación del psicólogo; psicología escolar; fracaso escolar.

\section{PSICOLOGIA E ESCOLA: UM ENCONTRO NECESSÁRIO}

Uma área de atuação do psicólogo que cresce nos últimos anos é a psicologia escolar/educacional, tanto nas redes de ensino como em espaços de educação não formal e de atendimentos à queixa escolar. Mesmo assim, ainda é comum psicólogos se formarem sem terem tido qualquer contato com uma escola, mesmo com toda a literatura produzida pela psicologia escolar em uma concepção crítica nos últimos vinte anos (Patto, 1999; Souza, 2009; Machado,1994; Freller, 2001).

Trabalhos como os de Souza (2009), Antunes (2008), Freller (2001) assinalam que a atuação do psicólogo escolar continua focada no indivíduo e em seu psiquismo. Ainda hoje, muitas crianças com dificuldades de aprendizagem são encaminhadas aos serviços de psicologia para a realização de um diagnóstico psicológico que justifique cientificamente a exclusão escolar. Na maioria dos casos, o diagnóstico baseia-se numa concepção inatista de homem e de mundo, que atribui ao sujeito a responsabilidade pela sua não aprendizagem. As consequências mais diretas desta explicação são a patologização e biologização dos problemas de aprendizagem, o que reforça a ideia do distúrbio de aprendizagem como uma anormalidade orgânica, fomentando cada vez mais a exclusão de alunos das classes menos privilegiadas da escola. As crianças, em sua maioria filhas de famílias da classe trabalhadora, acabam sendo avaliadas como desajustadas, desequilibradas, deficientes mentais, portadoras de distúrbios emocionais ou neurológicos, hiperativas, apáticas, traumatizadas, com disfunção cerebral mínima e tantos outros rótulos.

Estas avaliações transformam desigualdades sociais em diferenças individuais, com o entendimento de que a culpa de não aprender é dos alunos, que não têm capacidade para isso, de que são eles o grande problema da escola, os que os reduz a objetos, independentemente de suas condições sociais e políticas. O psicólogo que avalia essas crianças raramente vai à escola investigar as condições em que são produzidas as dificuldades de aprendizagem, baseando-se, nessa omissão, em técnicas limitadas e em jargões preconceituosos acerca da pobreza (Patto, 1999, 2000).

Sobre essas questões pode-se citar o trabalho de Souza (1996), que, investigando prontuários de casos de queixa escolar em clínicas-escolas de universidades em São Paulo, observou que a maioria deles não fazia menção à escola e ao processo de escolarização. Esses prontuários traziam a história de vida da criança levantada pela anamnese, pelos antecedentes de problemas mentais e pela situação socioeconômica familiar, com elementos para construir uma imagem da criança que, além de serem poucos, não auxiliavam na compreensão do motivo do encaminhamento. A autora também constata a presença de "jargões escolares", como "não sabe nada", "tem problema de aprendizagem", ou ainda, estereótipos como "está bem-cuidada, limpa, roupa adequada, cabelos penteados", "o pai é negro, a mãe é branca e Mariana é bem mestiça". Alguns prontuários chamavam a atenção pela inexistência de qualquer informação sobre a relação institucional que produzira a queixa: não apresentavam o nome da escola, nem dados sobre reprovação ou outros de igual importância.

Correia, Lima e Araújo (2001) também alertam a respeito do desconhecimento dos psicólogos sobre a escola e os processos de escolarização. Discutem seu papel no contexto escolar baseados em uma atuação alheia à conjuntura escolar, que desconhece a função educativa da escola. Segundo as autoras, a atuação do psicólogo, para ser capaz de superar a culpabilização do aluno, deve pautarse na análise da instituição educativa e no exame da eficiência e da qualidade do processo educacional, o que requer trabalhar junto com a equipe escolar e ter uma sólida formação teórica, no que se refere não só às teorias da psicologia, mas também à literatura educacional.

As análises de Patto (1999), Souza (1996, 2009), Souza (2007), Correia, et al. (2001) levam a uma questão mais ampla: a da formação de psicólogos. Acreditamos em uma formação em psicologia que possibilite intervenções apoiadas na compreensão dos inúmeros elementos que 
constituem a subjetividade em sua relação com a educação; ou seja, é necessário que o psicólogo compreenda como são organizadas as relações escolares, a dinâmica institucional da escola e os preconceitos engendrados no cotidiano escolar.

Nesta perspectiva, discutimos a inserção do estudante de psicologia na escola por meio de visitas a essa instituição. Tal estratégia de formação cria a possibilidade de o futuro psicólogo contatar-se com o cotidiano escolar e deparar-se com situações que vão além da imediata relação entre o psicólogo e o usuário. Assim, o objetivo deste texto é apresentar dois espaços de formação, construídos no trabalho docente no curso de Psicologia de uma universidade privada de São Paulo, que buscam pensar e construir uma formação voltada à compreensão e à atuação junto ao indivíduo concreto, a saber, a disciplina "Problemas de aprendizagem" e o estágio "Intervenção clínica em processos de aprendizagem".

\section{INSERÇÃO DO ESTUDANTE DE PSICOLOGIA EM ESPAÇOS EDUCATIVOS}

\section{A disciplina "Problemas de aprendizagem"}

Em 2007, quando começamos a trabalhar como professoras de um curso de Psicologia em uma Universidade privada da cidade de São Paulo, não havia no currículo a disciplina Psicologia Escolar ou estágios nessa área. O que mais se aproximava da possibilidade de discutir a inserção do psicólogo na educação era a disciplina Problemas de Aprendizagem, que era ofertada no $5^{\circ}$ semestre do curso e cujos conteúdos referiam-se à patologização da aprendizagem tendo como foco distúrbios e transtornos do aluno como, por exemplo, dislexia, transtorno de déficit de atenção e hiperatividade, discalculia, disortografia, etc. Aos poucos fizemos alterações no programa, introduzindo autores como Patto (1999), Machado (1994) e Freller (2001). Também acrescentamos ao estudo dos distúrbios a crítica aos seus critérios diagnósticos e ao processo de medicalização da educação (Moysés, 2001; Conselho Regional de Psicologia de São Paulo, 2010). Iniciamos, ainda, uma discussão sobre o desenvolvimento do psiquismo em sua relação com a cultura, tendo como referência autores como Vigotski (2000) e Winnicott (1975).

Passo a passo assumimos posicionamentos que levaram os alunos a questionar a própria Psicologia e tudo aquilo que estavam aprendendo a respeito de crianças na escola. A partir dos textos de Patto (2000), tínhamos subsídios para contestar a abordagem psicométrica, hegemônica na matriz curricular do curso.

A partir da leitura e discussão dos textos começaram a ocorrer algumas transformações nas concepções de psicologia dos estudantes, observadas em frases como: "Se os testes não servem para medirmos a inteligência da criança, por que precisamos aprendê-los?”. Ou questionavam: "Como vamos fazer para darmos diagnósticos para as famílias das crianças com problemas de aprendizagem?". Alguns estudantes, angustiados com o novo posicionamento, tentavam reafirmar o que já haviam aprendido, buscando discutir tais questões nas disciplinas de avaliação psicológica. Nesses momentos questionávamos: uma visão mais crítica com relação à escola e à criança começava a circular e aquilo que parecia angústia não seria a inquietação de se estar pensando de modo diferente?

A discussão acerca dos testes psicológicos está longe de se esgotar. O que colocamos em evidência é a existência de outros dispositivos utilizáveis pelo profissional, inclusive a relação interpessoal que se estabelece no momento e poderá delimitar a trajetória a seguir, com cada pessoa em particular. $\mathrm{O}$ discurso crítico sobre a avaliação da inteligência na escola parecia produzir muitas inquietações, como observa Patto (2000, p. 68).

O assunto é difícil por dois principais motivos: 1) chama a atenção para a má formação dos psicólogos; e 2) o uso de testes para fins psicodiagnósticos é, por lei, privativo dos psicólogos e está no centro de sua identidade profissional, o que faz com que a crítica provoque medo de perda dos pontos de referência.

A discussão acerca da abordagem psicométrica e do processo de medicalização da educação fez sentido para alguns estudantes, que começaram a rememorar a própria história escolar. Muitos cujas histórias de vida se pareciam com as discutidas nos textos da disciplina encontravam elementos que permitiam compreender a realidade escolar que tinham vivido.

De fato, acreditamos que estávamos movimentando os alunos no sentido de os tirarmos de uma situação de acomodação e suposto equilíbrio para um desmoronamento de suas ideias e certezas. Nesse momento, incluímos a visita à escola como um dos requisitos da disciplina, com o objetivo de conhecer e investigar a realidade escolar. Tal visita coroava as discussões teóricas realizadas na disciplina e tinha como objetivo permitir que os estudantes tivessem contato com o cotidiano escolar e sua problemática. 
Os alunos, em grupos de quatro ou cinco, iam para escolas públicas ou privadas, no período contrário ao da faculdade, de duas a três vezes, a depender do número de entrevistas que conseguiam realizar e de como eram recebidos pelas instituições. As escolas eram escolhidas pelos alunos e, em sua maioria, localizavam-se perto de seus bairros de origem. Após as visitas os alunos, além do relatório escrito, apresentavam seu trabalho aos demais de sua turma do curso de Psicologia, para que todos conhecessem as minúcias de cada lugar visitado.

Assim que os estudantes iniciavam as visitas, algumas "surpresas" começaram a aparecer: 1) a resistência da escola a recebê-los; 2) os laudos médicos ou psicológicos; 3) problemas referentes à desestruturação familiar.

Em relação à primeira "surpresa", alguns alunos relatavam dificuldades encontradas para serem recebidos pela diretora, pela coordenadora ou pelos professores. Visitas eram agendadas, mas na hora de serem recebidos a pessoa que seria entrevistada não estava presente ou ninguém sabia do que se tratava. Outras escolas, ainda, negavamse a receber qualquer aluno de psicologia para uma conversa, segundo o relato dos estudantes. Não é possível saber se a forma como nossos estudantes faziam o contato com a escola gerava esse tipo de resistência e se eles mesmos produziam a recusa da escola em recebê-los.

Quanto aos laudos médicos ou psicológicos, alunos surpreenderam-se ao descobrirem nas falas de professores a validação de laudos médicos ou de outros profissionais com relação aos possíveis distúrbios de aprendizagem das crianças e, mais ainda, quando percebiam o valor que era dado a esses laudos. Observaram professores que se arriscavam a afirmar que sabiam que determinado aluno tinha certo distúrbio (davam até o nome científico), mas não podiam "fazer nada", pois não tinham laudo comprovando suas hipóteses. Outros apontavam alunos da classe dizendo que tinham diagnósticos que indicavam determinado distúrbio de aprendizagem. Durante a apresentação do relatório em classe, discutimos com eles o que significa esta busca por um laudo, e apontamos a existência, nas escolas, de profissionais que têm uma visão diferenciada acerca do fracasso escolar e questionam, inclusive, a necessidade do psicólogo na escola.

Quanto à desestruturação familiar, os alunos traziam à discussão as falas dos professores e diretores das escolas visitadas que acusavam as famílias das crianças. A culpa pelas dificuldades relacionadas às questões escolares comumente era atribuída à família, a quem caberia toda a sorte de comprometimentos morais, o que a desvalorizaria em sua capacidade de cooperar com a escola na educação de seus filhos. As acusações partiam da ordem hereditária, passavam pela socioeconômica e chegavam até à cultural.

Após a visita, todos apresentavam suas observações e reflexões aos colegas da disciplina. Nesse momento, as discussões teóricas ganhavam vida e os estudantes de Psicologia demonstravam compreender as críticas ao processo de patologização do fracasso escolar, como também as críticas ao modelo psicométrico.

Como os grupos visitaram diferentes escolas, públicas e particulares, periféricas e centrais, bemestruturadas e abandonadas, os relatos permitiam a confrontação entre as diferentes realidades e forjavam uma discussão sobre as políticas públicas em educação e sobre a organização dos sistemas de ensino. $\mathrm{O}$ estudo dessas políticas, de noções de legislação educacional e de teorias pedagógicas tornava-se, então, uma necessidade. Estudantes que começavam a disciplina dizendo que não gostavam de psicologia escolar e de trabalhar com crianças terminavam o curso tendo uma melhor compreensão das muitas possibilidades de atuação do psicólogo na área.

As discussões ocorridas no bojo da disciplina Problemas de Aprendizagem foram aprofundadas no estágio Intervenção clínica em processos de aprendizagem.

\section{O estágio "Intervenção clínica em processos de aprendizagem"}

O estágio nessa área surgiu a partir da grande demanda por atendimento aos problemas de aprendizagem na clínica-escola da universidade (70\% das crianças encaminhadas para atendimento). Tradicionalmente, esse estágio era denominado Intervenção Psicopedagógica, mas tanto seu nome como sua concepção foram alterados em uma reforma curricular do curso em 2006. Até então o estágio caracterizava-se como atendimento clínico à criança com problemas de aprendizagem, enquanto a mudança focou o processo de aprendizagem dentro do contexto escolar.

Nessa mudança curricular, o estágio passou a ser orientado pela leitura de autores embasados em uma concepção crítica de psicologia escolar, citados na introdução deste trabalho, bem como em concepções teóricas que analisam o desenvolvimento do psiquismo em sua relação com a cultura (Vigotski, 2000; Winnicott, 1975), dependendo da opção teórica de cada supervisor. 
Em 2007, além do atendimento à criança e à sua família, foi introduzida a obrigatoriedade da visita à escola. Esta visita ajudava a compreender elementos importantes da vida da criança, particularmente os relacionados à produção da queixa escolar. Um dos objetivos era a compreensão global do processo de aprendizagem, e não só da produção da dificuldade. Nesse sentido, o olhar era dirigido para as relações escolares.

Inserir a visita à escola surtiu efeitos interessantes na experiência do estagiário e de seu supervisor, na experiência de vida da criança em atendimento e de sua família e na das pessoas das escolas visitadas. As experiências do estagiário em ação ajudaram a compreender a especificidade do estágio, permitindo que encontrassem alternativas de intervenção sem cair na redução de classificar a criança e sua família como desinteressadas do processo de escolarização ou portadoras de uma patologia escolar.

$\mathrm{Na}$ supervisão, o estagiário era conscientizado da importância de fazer o contato com a escola que a criança estudava, pois era nesse espaço que se apresentava um problema para ela e para as pessoas envolvidas nesse processo. Incluir a escola na compreensão que se fazia a respeito da escolarização da criança ou adolescente ampliava o campo de estudo envolvido: pessoa-família-escola-sociedade.

Visitar a escola implicava ter o nome, o endereço e o telefone da instituição para contato. Uma surpresa que a princípio se apresentou na supervisão era o desconhecimento de algumas crianças sobre os dados de sua escola, por diferentes motivos: haviam mudado muitas vezes, a criança não os aprendera e/ou não lhes foram ensinados, aquilo não era importante, ou outro motivo que fugia do nosso controle. Esse era um conhecimento que, ao lado de tantos outros, requeria atenção e aprofundamento, pois envolvia a criança em sua relação com a instituição que a recebia diariamente.

Durante os atendimentos, na relação do estagiário com a criança esse aspecto era abordado como um conhecimento importante a respeito de si e que seria interessante ser descoberto por ela própria. Como isso seria feito era motivo de conversa na sessão: o estagiário explicitava a importância de conhecer onde ela estudava, como as disciplinas eram ensinadas, como os profissionais lidavam com os alunos, e discutia que sem o nome e o endereço da escola e o nome de uma pessoa para conversar seria impossível conseguir isso.

Algumas crianças ou adolescentes traziam, nesse momento, angústias relacionadas à escola: " $O$ que você vai fazer lá? Ninguém gosta de mim"; ou - "Não vai adiantar nada, a professora me odeia"; ou ainda "Eu nem gosto dessa escola, não precisa ir" palavras que veiculavam o sentimento de se sentir excluído, de não pertencer àquele grupo de pessoas. Nesse ponto abria-se a possibilidade de lidar com uma das necessidades básicas de qualquer ser humano, a de pertencer a grupos, começando pelo familiar e seguindo com a escola ou outras instituições que se passe a frequentar.

As palavras comunivam também certa separação da vida escolar, como se esta não fizesse parte da vida como um todo e impedisse a integração de questões relacionadas aos alunos e professores que aparecem no espaço escolar por causa da diferença das relações envolvidas na escola e pelo despreparo para lidar com elas, e não por um eventual problema de aprendizagem do aluno.

Lidar com essa complexidade fortalecia os estagiários e as crianças, que construíam juntos esse conhecimento, o de conseguir informações sobre a escola, e outros que se desdobravam nos encontros terapêuticos. A criança colocava em movimento suas relações com pessoas de sua família e da escola, as quais iam desde um papel escrito pela mãe solicitando as informações necessárias, principalmente sobre quem procurar para obtê-las, até ela mesma tentar escrever as informações para levar para o estagiário.

Dependendo da singularidade de cada história, conseguir esse endereço podia durar o semestre todo. Ao lado dessa pesquisa que a criança e sua família faziam, o atendimento ia acontecendo pautado na ética do encontro interpessoal, cuidando das condições favoráveis ao existir e pensar humanos, para a criança e para as pessoas que se relacionavam com ela.

Em outras histórias, o contato com a escola aconteceu no meio do semestre e houve oportunidade para troca, com os professores, de informações sobre o desenvolvimento do aluno, e em muitos casos a criança passou a ser vista como alguém com capacidade para aprender.

Houve histórias em que o contato aconteceu tão logo a escola foi procurada e em que a criança foi rotulada e considerada, quanto a seu processo de desenvolvimento, como alguém com uma doença que precisava ser medicada com urgência. Nesses casos foi difícil argumentar com o posicionamento pautado no desenvolvimento humano, pois a cristalização das ideias em torno da patologia da aprendizagem era dominante.

Assim, mesmo que a visita não se concretizasse ou fosse infrutífera em relação a trocas de informações sobre a escolarização de determinada criança, ela era o complemento necessário para a compreensão do 
processo de aprendizagem vivido pelo aluno naquele momento.

Conhecer a escola real da criança, a que fazia parte do seu dia a dia, e, a partir dela e da disponibilidade das pessoas que trabalhavam com ela, poder levantar o modo como procediam em relação ao processo de escolarização passou a ser uma necessidade de atendimento. Compreender o que acontecia na relação aluno-professor, aluno-disciplinas, aluno-escola tinha mais relevância do que saber seu coeficiente de inteligência ou dados da anamnese. A criança podia, junto com o estagiário, integrar a escola à sua vida e compreender sua coparticipação em seu processo de aprendizagem.

Muitos estagiários puderam rever sua vida escolar e os impactos desta em sua forma de aprender e de viver. Lembrando-se de suas experiências escolares, compreenderam como algumas de suas dificuldades foram construídas no processo de escolarização e repensaram seus planos profissionais. Ao final, escreveram um relatório em que avaliavam as mudanças produzidas na sua forma de pensar e atuar:

Existem mitos em relação ao processo de aprendizagem e acho que é válido ressaltar o mito de que a criança que não aprende tem problema e que este só encontrará solução fora da escola com tratamentos especializados. Isso não é verdade, toda criança tem condições de aprender $e$ a escola é a peça principal juntamente com a família, mesmo tendo a oportunidade de passar por um tratamento fora da escola.

Na minha opinião o estágio em Intervenção Clínica em Processos de Aprendizagem foi muito proveitoso, porque o trabalho não se restringiu aos atendimentos ao paciente. A busca pela compreensão dos processos que podem ter levado a uma patologia do aprender envolve aspectos como a análise da dinâmica familiar e as interações que ocorrem na escola. Por isso é imprescindivel o conhecimento dessas relações. Nesse sentido, fizemos Entrevistas semiestruturadas com os pais, jogo fraterno e uma visita à escola a fim de obter uma melhor compreensão do caso.

\section{CONSIDERAÇÕES FINAIS}

Mesmo com todas as críticas ao processo de produção do fracasso escolar e à atuação do psicólogo escolar numa perspectiva reducionista, tais modelos de compreensão e de atuação insistem em ser reeditados.
Assim, nunca é demais ressaltar que o fracasso escolar não pode ser entendido como problema que se encerre no aluno, concebido como ser natural ou social/natural. Deve ser compreendido como um processo construído nas relações escolares, nas histórias de vida das pessoas envolvidas, nas relações institucionais e no contexto maior da estrutura social, como produto da história.

Dessa forma, é urgente a busca por outros modos de formação do psicólogo, dadas as dificuldades de uma escolarização que caminhe num sentido oposto ao da psicologização da educação. Essa busca exige a reconstrução da identidade do psicólogo no contexto educacional e uma ampliação da concepção da queixa escolar que focalize não só a criança, mas também a identificação de fatores escolares e sociais, de modo a tornar possível uma intervenção que produza desenvolvimento humano.

\section{REFERÊNCIAS}

Antunes, M. A. M. (2008). Psicologia escolar e educacional: história de compromissos e perspectivas. Psicologia Escolar $e$ Educacional 12(2), recuperado em 24 janeiro, de 2011 de, http://www.scielo.br/scielo.php?pid=S1413$85572008000200020 \&$ script $=$ sci_arttext.

Conselho Regional de Psicologia de São Paulo. (2010). Dislexia: subsídios para políticas públicas. São Paulo: CRPSP. Recuperado em 20 agosto, de 2010, de http://www.crpsp.org.br/crp/midia/cadernos_tematicos/8/frames/fr _indice.aspx.

Correia, M. F. B.; Lima, A. P. B., \& Araujo, C. R. de. (2001). As contribuições da psicologia cognitiva e a atuação do psicólogo no contexto escolar. Psicologia Reflexão Crítica, v. 14 (3), 553-561.

Freller, C. C. (2001). História de indisciplina escolar: o trabalho de um psicólogo numa perspectiva Winnicottiana. São Paulo: Casa do Psicólogo.

Machado, A. M. (1994). Crianças de classe especial. São Paulo: Casa do Psicólogo.

Moysés, M. A. A. (2001). A institucionalização invisível: crianças que não aprendem na escola. Campinas-SP: Mercado das Letras.

Patto, M. H. S. (1999). A produção do fracasso escolar: histórias de submissão e rebeldia. São Paulo: Casa do Psicólogo.

Patto, M. H. S. (2000). Para uma crítica da razão psicométrica. In M.H.S. Patto, Mutações do cativeiro: escritos de Psicologia e política. (pp. 65-83.) São Paulo: Hacker ; Edusp.

Souza, B. P. (Org.). (2007). Orientação à queixa escolar. São Paulo: Casa do Psicólogo.

Souza, M. P. R. de. (1996). A queixa escolar e a formação de psicólogos. Tese de doutorado não-publicada, Instituto de Psicologia, USP, São Paulo.

Souza, M. P. R. de. (2009). Psicologia Escolar e Educacional em busca de novas perspectivas. Psicologia escolar e educacional, 13(1). Recuperado em 24 janeiro, de 2011 de, http://www.scielo.br/pdf/pee/v13n1/v13n1a21.pdf. 
Vigotski, L. S. (2000). A construção do pensamento e da linguagem. São Paulo: Martins Fontes.

Winnicott, D. W. (1975). O brincar \& a realidade. Rio de Janeiro:

Recebido em 01/11/2010 Imago.

Aceito em 09/03/2011

Endereço para correspondência:

Flávia da Silva Ferreira Asbahr. Rua Caraibas, 383 ap. 31, CEP 05020-000, Pompéia São Paulo-SP, Brasil.E-mail: flaviasfa@yahoo.com.br. 